\title{
A Challenge to Boghossian's Incompatibilist Argument
}

\section{Josep E. Corbí}

1. Let me rehearse, to begin, the core of Boghossian's incompatibilist argument. From premises

(1) If I have the concept of water, then water exists.

(2) I have the concept of water,

it follows that

(3) Water exists.

The paradox arises as we realize that (3) is clearly not knowable $a$ priori, but (1) and (2) are. (2) holds ' $a$ priori' because, according to Boghossian, it "just is the view that I have called the doctrine of privileged self-knowledge" (p. 202). The core of the paper is devoted, though, to argue that an externalist (i.e., someone who holds the view that "... facts external to a thinker's skin are relevant to the individuation of (certain of) his mental contents" (p. 199). is bound to concede that (1) is knowable ' $a$ priori'. It would follow that, contrary to intuition, (3) can be known a priori since is the conclusion of an inference that relies on two premises that are, in 
turn, knowable a priori. All this is envisaged by Boghossian as an argument for incompatibilism, that is, for the claim that Externalism and Privileged Access are inconsistent because their combination leads to utterly absurd consequences.

In the present comment, however, I will advocate for compatibilism. My challenge to Boghossian's incompatibilist argument divides into two steps. At a first stage, I will focus on premise (2), and explore to what extent the privileged access that a subject has to her own mental contents may ensure the ' $a$ priori' knowability of premise (2). To this purpose I will compare my access to the truth of the claim ' $I$ have the concept of water' with my access to the truth of claims like 'I know how to ride a bike', 'I master the concept of checkmate', 'I think I have a checkmate in two moves', and 'I think there is some water in the fridge'. The upshot will be that, contrary to what premise (2) indicates, I cannot know ' a priori' that I master a certain concept, since it seems clear that it could occur that I would wrongly believe that I master a certain concept. This does not amount to denying, as we shall see, a privileged or special access to one's own concepts, but not so privileged as to exclude the possibility that certain facts of the world may come to challenge one's beliefs in this respect.

At second stage, I will shift to premise (1). I will then insist that the externalist only needs to grant this premise on the assumption that water is a natural kind concept, and not merely on the assumption that 'water' is aimed at expressing a natural kind concept. To reach this conclusion, I will certainly have to rebut Boghossian's remarks to the contrary. But, if I would succeed, then it would follow that the externalist, even if she should grant the ' $a$ priori' knowability of premise (2), would not have to concede that the fact that water exists is also knowable 'a priori'. For her knowledge of premise (1) would rest on an assumption (i.e., that water is a natural kind concept) whose truth can only be known 'a posteriori'. As a result, Boghossian's incompatibilist argument would be under some pressure.

2. Let us consider premise (2). At the outset, the Privileged Access doctrine is presented like this: "I can know without empirical investigation (a) that I am entertaining a thought; (b) that it has a particular conceptual content, and (c) that its content is that water is wet" (p. 198). This is referred to as the traditional doctrine. And, strictly speaking, Boghossian is supposed to explore to what extent this doctrine is consistent with Externalism. I must confess that, faced with this rather general characterization of Privileged Access, 
I feel uncertain as to how much this doctrine should comprise and, relatedly, how plausible it may finally be. In an attempt to elaborate this perplexity, let me consider a few cases that may help us to determine in a slightly more precise way the content of a plausible Privileged Access doctrine, and see whether, on such a doctrine, I could know 'a priori' premise (2).

2.1. Undoubtedly, I know that I know how to ride a bike. How does I get to know about this ability of mine? There is a trivial sense in which I needn't carry out any empirical investigation to have this valuable piece of knowledge. But, indeed, none would deny that my knowing that I possess that ability depends on my knowledge of certain facts of the world that involve my previous performances on a bike.

Take the mental content ' $I$ know how to ride a bike'. Adult people are rarely wrong in this respect, but, of course, one would not be surprised if a child may mistakenly believe that she knows how to ride a bike or how to swim and, more typically, if a child would unwarrantedly have that kind of belief. Thus, I once heard of someone who, being otherwise more or less a normal person, decided that he had learned how to swim by studying how other people were performing and, after this conscientious study, dived into the swimming pool. Fortunately, there was someone around to rescue him. What strikes me about this case is not that this person had the false belief that he knew how to swim, but rather that he could have acquired that belief by such manifestly inadequate means. Watching other people's performance is not a means (at least, ordinarily) to learn swimming. For a certain practice in that art seems indispensable. In general, we assume that, typically, a human being can only justifiedly belief that she knows how to swim if she has gone through a certain process of training.

A consequence of this is that certain public facts about me must be true, for me to justifiedly believe that I know how to swim and, thereby, for me to know that I know how to swim. It does not sound then reasonable to claim that I can know 'a priori' that I have this ability. It is true that, in a trivial sense, in order to have this kind of knowledge I needn't carry out any empirical investigation. But in this trivial sense I also know without empirical investigation that water exists.

The second moral I want to draw from this example goes like this. It is not accidental that, in order to describe a situation where someone unjustifiedly believes that he knows how to swim, I have shifted to the attitudes of children or the case of a relatively weird person. In fact, we tend to assume that, among normal adult people, 
this kind of thing does not happen but very rarely. But how is it? Does this reveal a special access to one's abilities on the side of normal adult people? Notice that I say 'special', not 'a priori' or 'independent of one's knowledge of some particular facts of the world'. Yes, special, but not mysterious: it has to do with the way 'normal adult people' and their beliefs about their own abilities are individuated. $\mathrm{X}$ is a normal adult human being only if beliefs about her abilities are typically acquired by means that justify her in having those beliefs. It follows from this metaphysical principle, that a human being that does not satisfy this condition is weird or childish or, at least, temporarily weird or childish.

2.2. What is the relevance of these stories about swimming pools and bikes to the knowledge of one's mental contents? To answer this question, let us see how our remarks above apply to cases where beliefs about one's mental contents are involved. I am playing chess with my friend Michael. I know that I believe that I have a checkmate in two moves unless Michael protects his king with a certain improbable move. I try hard to hide my excitement so that my friend should not suspect and engage in any extraexploration of the available moves.

I have a special access to my belief, an access that is alien to my behavior and expressions at that particular moment. That is why the hiding maneuver is at all possible. Yet, my having such a belief presupposes a certain mastery of the rules of chess and, more specifically, of the concept of checkmate.

It sounds clear, however, that someone may wrongly believe that she masters the concept of checkmate or that she masters the rules of chess. This is, of course, quite common during the process of training. Moreover, it is quite strange that someone would believe that he has a mastery of those rules and concepts without having engaged in certain practice with chess or related games. Once again, it seems that the means by which ordinary people acquire the belief that they master a certain concept are also means that justify their having such a belief. There is room, indeed, for an ordinary person exceptionally acquiring that belief in an inappropriate way, or for weird people to unjustifiedly believe that they master a certain concept. This sort of disadjustment has a limit beyond which it would be unclear that the subject at stake is actually having a belief about her mastery of a certain concept.

So, it seems that my justifiedly believing that I master the concept of checkmate is not independent of the correctness of some past (and, for similar reasons, future) performances of mine. Moreover, the idea of 'a priori' knowledge seems to comprise an internalist element: 
knowing that $\mathrm{p}$ 'a priori' involves my being able to provide certain reasons to justify my believing that $p$-reasons that, indeed, should not mention any particular facts of the world. So, if I should know ' $a$ priori' that I master the concept of checkmate, I should be able to provide some sort of evidence that is independent of what occurs in the world. But it seems that this cannot be done, that I should ultimately include within that evidence the reasons why I believe that I performed correctly in the past or, alternatively, supply some further examples of my current capacities. It sounds then that my knowledge of the concepts I master is not ' $a$ priori', even if it is special. And the source of this specialness, like in the riding of a bike, derives from some metaphysical principles of individuation. These principles ensure that when a normal adult person claims ' $I$ master the concept of checkmate', she typically needn't provide any justification. The problem for Boghossian's argument arises as we realize that, in those situations where that person would need to justify the truth of her belief, the kind of evidence that may supply could hardly be gathered ' $a$ priori'.

2.3. All this has quite direct implications for the epistemic status of premise (2), namely: 'I have the concept of water'. It is quite clear, and follows from my previous remarks, that someone (typically, a child) may mistakenly believe that she has the required mastery of the concept of water and, also, that any attempt that this person may undertake to justify her belief that she has the mastery at stake will require that this person should mention her knowledge of certain facts of the world. So, once again, the knowledge that an adult person may have of premise (2) is special - since she needn't provide any justification of it but in exceptional circumstances: there are some metaphysical individuation principles that ensure that adult persons can't be but exceptionally wrong in this respect- but not a priori. ${ }^{1}$

2.4. To sum up this first step of my discussion, I could say that I have tried to make room for the specialness of a subject's access to her own concepts without being committed to the implausible claim that they are known 'a priori', that is, independently of our knowl-

${ }^{1}$ In these remarks, I have focused on a subject's beliefs about the mastery of a certain concept, since that is the nature of the belief stated in premise (2). Yet, it is clear that the traditional doctrine about Privileged Access tends to target a different kind of belief, namely: beliefs about a certain mental content like 'I think I have a checkmate in two moves'. The special access that a subject may have to her own mental contents differs in some important respects from the special access to the concepts that she may master. This is, however, a point on which I cannot dwell now. 
edge of particular facts of the world. The intuition is that, in those scenarios were the subject is recognized as having privileged access to her concepts, the conditions under which a subject acquires a belief about her concepts typically coincide with those that justify that belief. All this casts doubt on Boghossian's argument insofar as those conditions involve particular facts of the world whose instantiation cannot be known 'a priori'.

3. Let us now shift to premise (1). At first sight, it sounds that an externalist would only concede its truth on the assumption that

\section{(A) water is a natural kind concept.}

Moreover, an externalist will have reason to deny that (A) could be known 'a priori', since the truth of (A) would depend, on her account, on some environmental facts. ${ }^{3}$ This contention does not

${ }^{2} \mathrm{My}$ approach surely exploits some aspects of the treatment of self-knowledge that Donald Davidson and Tyler Burge have suggested in some of their writings (cf. Davidson (1987) and Burge (1989)). They tend to insist that self-knowledge is not a mystery because the conditions for the individuation of mental content coincide with the conditions for believing that one has such contents. So, there is little (or no) room for a gap between having a certain thought and believing that one has that thought, and this vigorous metaphysical connection seems to ensure the transition from believing that one has a certain thought to knowing that one has it. Relatedly, I have been pointing out that the conditions for the individuation of the mastery of concepts (and mental contents) typically coincide with the conditions for justifiedly believing that one masters that concept (or possesses a certain mental content).

Yet, I have tried to belabor this intuition by highlighting, firstly, that such a coincidence has partly to do with the fact that normal adult human beings are individuated in such a way that the means by which they may acquire the mastery of a concept are also the means by which they acquire the belief that she masters that concept. Secondly, I have insisted that it is compatible with this metaphysical principle that, occasionally, a subject should unjustifiedly believe that she masters a certain concept $\mathrm{C}$ and, consequently, that one must leave some room for disadjustment between believing that one masters a concept and mastering it. My main point has, in any case, been that the combination of all these elements allows us to explain why a subject's knowledge about the concepts that she masters may be special, but not ' $a$ priori', since the kind of reason she may mention to justify her belief would necessarily comprise her knowledge of some particular facts of the world.

${ }^{3}$ This is a point that Jessica Brown (cf. Brown (1995, p. 154)) seems to concede. She seeks, however, to neutralize the impact of assumption (A) by stressing that there is still some kind of ' $a$ priori' knowledge of the world that the externalist is bound to recognize. Thus, Burge would have to accept that, "for example, from the fact that he [Oscar] knows a priori that he has a thought involving the concept of water, he could come to know a priori that (either his environment 
necessarily conflict with the Privileged Access doctrine or even with the 'a priori' knowability of premise (2). For one could reasonably claim that my knowing that I have the concept of water does not entail that I know that water is a natural kind concept. This is, in fact, a point that Boghossian seems to grant and, therefore, I will save you the rationale. ${ }^{4}$ In any event, if all this turned out to be true, then premise (1) could not be known 'a priori' since it relies on

contains water and the concept of water is a natural kind concept, or he is part of a community which has the concept of water)" (Brown (1995, p. 155)). In my view, this line of reply significantly debilitates the initial argument, whose strength derives from the neat conviction that one cannot know a priori that water exists or any other particular fact of the world. For, on Brown's disjunctive proposal, it sounds now quite natural to grant that, if a subject can know ' $a$ priori' that she has a certain concept, she can also know ' $a$ priori' that the world must be such as to enable her to possess that concept. Furthermore, assuming - as Boghossian's argument does - that the externalist doctrine is knowable ' a priori' seems almost equivalent to assuming the ' $a$ priori' knowability of the fact that the disjunctive condition is part of those enabling circumstances.(Cf. Miller (1997) for a discussion of this point, and Burge (1993) for the notion of ' $a$ prior' that may be involved). Hence, if one would be inclined to disapprove of the ' $a$ priori' knowability of the latter, one would have to dismiss the ' $a$ priori' knowability of externalism and, as a result, the incompatibilist argument would be damned.

In any event, Brown's line of defense is not only quite inadequate, but unavailable to Boghossian because Brown's strategy presupposes that water would be atomic or compound depending on some external circumstances and, as we shall soon see, this is something that Boghossian cannot accept.

${ }^{4}$ In any event, it is not hard to motivate the claim that someone may know that she has the concept of water without knowing that water is a natural kind concept; specially, if one assumes the ' $a$ priori' knowability of premise (2).

It seems clear that different individuals may have the same concept $\mathrm{C}$ despite variations in their respective degree of mastery of it. This seems a precondition for several individuals to have the same thought, the same desire or belief, since identity of thoughts presupposes identity of concepts. Yet, a consequence of this fact is that the possession of concept $\mathrm{C}$ is consistent with a limited access on the side of the subject to the elements involved in that concept. This limited access seems to be a sequel of the identity of concepts across individuals.

If this were true, then I could claim that someone may possess the concept of water without having a complete mastery of that concept. And, more interestingly, that someone may know that she possesses the concept of water without knowing every element involved in the concept of water. Still, we should need to motivate a more particular claim, namely: that someone may know that she possesses the concept of water without knowing a particularly central feature of it, that is, that it is a natural kind concept. Let us see how this could be done.

Consider now two well-known cases of concepts that aimed at designating a natural kind: phlogiston and caloric. It sounds plausible to describe the situation as follows: at a certain stage in the history of science, scientist justifiedly believed that phlogiston and caloric were two natural kind concepts, but in time they discovered that they were wrong, that there is no natural kind that they may 
an assumption to which we have only an ' $a$ posteriori' access and, consequently, Boghossian's incompatibilist argument would fail.

4. But, indeed, Boghossian is quite reluctant to grant that an externalist could only be forced to accept premise (1) on assumption (A). For, as he points out, a Twin-Earth argument can be run even if 'water' does not actually express a natural kind concept, but only aims at being so:

The reason this particular objection doesn't succeed is that it is quite clear that we can run a TE experiment on a word that doesn't actually name a natural kind. Suppose we had such a word, W, on Earth. Then, to get a successful TE experiment, all you need to do is describe a Twin situation in which, although the users of the word type W are functional and molecular duplicates of their counterparts on Earth, W does name a kind in the Twin situation. Provided intuition still has it that the extension of Earthly tokens of W are different from the extension of the Twin tokens of W - which of course they will be since the extension of the former will be empty and the extension of the latter won't be- the experiment will succeed. (P. 205).

designate. Nothing like that has occurred with the concept of water precisely because there is empirical evidence that there is a single substance that plays a certain causal role $\mathrm{R}$. This is a contingent fact.

It seems to me that a similar intuition lies behind David Lewis' and Jaegwon Kim's (Cf. Lewis $(1970,1994)$ and Kim (1992))remarks about how multiple realization may pose a problem as to the causal efficacy of functional properties. The fact that 'human pain' designates a property depends on the rather contingent fact that the functional role that is proper to pain has the same realization in every member of the human species. It is perfectly intelligible that we could discover, for instance, that 'human pain' is multirealized and, in that case, one would have to claim that such phrase does not pick up a property but only a functional role. I guess that what goes for 'human pain', holds for 'water' as well: it is intelligible that we could have discovered that 'water' does not designate a property, but simply picks up a functional role. This is not something that we know ' $a$ priori'.

To see the relevance of this discussion to our present point, I could firstly say that it follows from the previous remarks that people that master the concepts of human pain, water, caloric, or phlogiston may discover, after empirical investigation, that some of such concepts do (or don't) have a referent, do (or don't) designate a property. So, if one is supposed to have 'a priori' access to one's concepts, then the fact that a term has a referent, that it designates a property, it is not something that one knows by the mere fact of knowing that one possesses the concept that such a term expresses. It seems then that, at least those who acknowledge the ' $a$ priori' knowability of premise (2), must recognize that someone may know that she has the concept of water without knowing that water is a natural kind concept. 
I suspect, however, that this sort of consideration may be both wrong and irrelevant.

a) Let me indicate firstly why I think it may be irrelevant. Suppose I concede that a Twin-Earth experiment can be run on a word W which on Earth does not express a natural kind concept, my question is: why should this affect my claim that an externalist only needs to concede premise (1) on assumption (A)? It is true that, if Boghossian is right, a term may be TE-eligible even if, on Earth, the corresponding (A)-premise does not hold with respect to it. But my previous line of reasoning is not merely saying that "in addition to aiming to express a natural kind, a word must actually name a natural kind, if it is to be Twin Earth-eligible" (p. 205), which is the explicit target of Boghossian's reply. What I am insisting is that an externalist only needs to concede (1) if (A) is true and, in this respect, it seems clear that the fact that a term is TE-eligible does not guarantee that an externalist should concede that the corresponding (1)-premise is true with regard to the concept that word W expresses on Earth, since, as Boghossian himself insists, a word $W$ may be TE-eligible even if the corresponding (1)-premise is false on Earth. It sounds then that in order to admit (1), the externalist needs more than TE-eligibility, she needs (A).

b) Let us now see why I suspect that Boghossian's considerations in the quote above are wrong or, in other words, the reasons why I doubt that a Twin-Earth experiment could be run on a word W which does not express a natural kind concept on Earth. The reason is this. Putnam's Twin-Earth argument relies on the assumption that natural kind terms contain a tacit indexical element, that their extension and referent is irreducibly fixed by means of an ostensive definition like, for instance: "'water' is stuff that bears a certain similarity relation to the water around here". ${ }^{5}$ Or, in other words, 'water' designates a liquid like this. Boghossian takes it that for a given word W, even if it is not a natural kind term on Earth, it could be so on Twin-Earth. My question is, though: how could the extension and reference of $\mathrm{W}$ on Twin-Earth be determined? What sort of ostensive definition could one employ to that purpose? Let us consider a pair of possibilities:

\footnotetext{
${ }^{5}$ Putnam (1975, p. 234). By saying this, I am not committing myself to the claim that 'water' is an indexical term, that is, that 'water' behaves like indexicals in every crucial respect. To put it in Burge's terms, what I am claiming is that having beliefs about water "requires that one be in not-purely-context-free conceptual relations to the relevant entities. That is, one must be in the sort of relation to the entities that someone who indexically refers to them would be". (Burge (1982), p. 106).
} 
i) One might treat Twin-Earth as if it were another planet with real people, trees, and rivers on it. In such a case, we can make sense of someone providing an ostensive definition of word W on TwinEarth. But, no wonder, this won't serve to the purposes of Boghossian's incompatibilist argument. For, in that case, it would be an empirical question whether $\mathrm{W}$ is a natural kind term on Twin-Earth and, hence, TE-eligibility would still depend on some empirical facts.

ii) Suppose, on the contrary and most reasonably, that TwinEarth refers to a counterfactual situation. How do we produce ostensive definitions in counterfactual situations? How do we point to a certain region in the counterfactual space? It sounds that the individuation of those situations is essentially parasitic upon some actual indexicalizations: it would be like this pointing but differing in that and that respect. Now, Boghossian's scenario is such that we could not actually point to any natural kind in defining the word W, since there is no such natural kind. So, how could we define a natural kind term in the Twin-Earth counterfactual situation? At first sight, it may sound that we have quite a simple procedure, namely:

(P) 'W' designates the natural kind that on Twin-Earth accomplishes such and such functional role.

Yet, this procedure clearly falls short of what a natural kind term requires. It is essential to a natural kind term that one could discover that some aspects of the functional role initially employed to individuate that natural kind do not belong to it, are not properties of such natural kind. But this kind of discovery is trivially excluded by procedure P. This epistemic circumstance is not alien to the semantics of natural kind terms, since one of its crucial functions is to allow speakers to refer to the same stuff despite variations in their knowledge of its functional role. Hence, a term whose extension is fixed by that procedure $\mathrm{P}$ is not a natural kind term. But, how else could the reference and extension of word $W$ in the Twin-Earth counterfactual situation be fixed so that it could operate as a natural kind term? This is, perhaps, the form that my second question to Boghossian may adopt. In any event, it is obvious that Putnam's Twin-Earth experiment is not at all prey to this kind of objection: Twater is the stuff that has on Earth the same functional role as water on Earth, and this holds stable across variations in our knowledge of that functional role.

5. I conjecture, to close, that Boghossian would be dissatisfied with my line of reasoning on point (a). For, he would argue, I am assuming that word W would not only express a different concept on 
Earth and Twin-Earth, but also a concept of a different nature: one would be a natural kind concept, but not the other. And, faced with this situation, the externalist would have to acknowledge that $\mathrm{W}$ on Earth would be a compound concept and on Twin-Earth an atomic one. And Boghossian is quite reluctant, in virtue of some metaphysical reasons, to accept that the atomicity or compositionality of a concept should depend on external circumstances such as those that the externalist mentions:

A concept's compositionality is exclusively function of its internal 'syntax' and can't be contingent upon external circumstances in the way the present proposal would require. (P. 208).

In the face of this, I would like firstly ask for some remarks as to the kind of metaphysical reasons that Boghossian may have in mind, since his contribution is quite hermetic in this respect.

Secondly, I would also welcome any comments as to how I should interpret the distinction between atomic vs. compound concepts. In the light of the rather scarce remarks that figure in the paper, I am inclined to say that, according to Boghossian:

A concept is compound if it is solely individuated in terms of a functional role

while, given that the distinction is assumed to be exhaustive:

A concept is atomic if and only it is not solely individuated in terms of a functional role.

It follows that, by definition, natural kind terms are atomic, and general terms that fail to be natural kind are equally by definition compound. It seems, then, that according to the externalist, the syntax of a concept should depend on certain external circumstances. But, according to Boghossian, this cannot be. Yet, insisting on this point, without providing any further motivation, sounds like begging the question against the externalist. For the externalist, in claiming "that facts external to the thinker's skin are relevant to the individuation of (certain of) his mental states" (p. 199), seems to be assuming that the individuation of the nature (as natural kind concepts and, by definition, as atomic) of some of the concepts involved in such mental states also depends on facts external to the thinker's skin.

6. With this I close my exposition of the reasons why I think that an externalist needn't concede that she can know (1) 'a priori'. Moreover, in my revision of premise (2), I concluded that a reasonable 
account of privileged access does not supply ' $a$ priori' knowledge about whether one masters a certain concept. So, if I am right, there is no reason why the combination of externalism and the privileged access doctrine should lead to 'a priori' knowability of the fact that water exists. ${ }^{6}$

\section{REFERENCES}

Boghossian, P. (this volume), "What the Externalist can know A Priori". Brown, J. (1995), "The Incompatibility of Anti-Individualism and Privileged Access", in Analysis, 55, pp. 149-156.

Burge, T. (1982), "Other Bodies", in A. Woodfield (ed.), Thought and Object. Essays on Intentionality, Oxford, Clarendon Press, pp. 97-120. (1988), "Individualism and Self-Knowledge", in Journal of Philosophy, 85/11, pp. 649-63.

- (1993), "Content Preservation", in The Philosophical Review, vol. 102, no. 4, pp. $457-488$.

Davidson, D. (1987), "Knowing One's Own Mind", in The Proceedings and Addresses of the American Philosophical Association, 60, pp. 441-58.

Kim, J. (1992), "Multiple Realization and the Metaphysics of Reduction", in Philosophy and Phenomenological Research, 52, pp. 1-26.

Lewis, D. (1970), "How to Define Theoretical Terms", in Journal of Philosophy, 67, pp. 427-46.

Lewis, D. (1994), "Lewis, David: Reduction of Mind", in S. Guttenplan (ed.), A Companion to the Philosophy of Mind, Oxford, Basil Blackwell, pp. $412-431$.

Miller, R.W. (1997), "Externalist Self-Knowledge and The Scope of The A Priori", in Analysis, 57, pp. 67-75.

Putnam, H. (1975), "The Meaning of 'Meaning" ", in H. Putnam, Philosophical Papers v. 2: Mind, Language and Reality, Cambridge, Cambridge University Press, pp. 215-271.

${ }^{6}$ Earlier drafts of this text have significantly benefited from comments by Carlos Moya, Tobies Grimaltos, Josep L. Prades, and Marcelo Sabatés. Research for this paper have been funded by the Spanish Government's DGICYT as part of the projects PS-03-0178 and PB93-1049-C03-02. My thanks to this institution for its generous help and encouragement. 


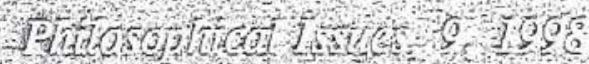

\title{
(a) (I)
}

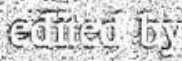

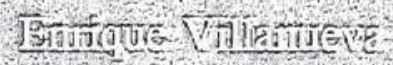

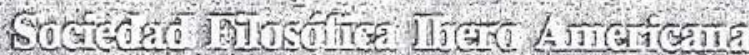

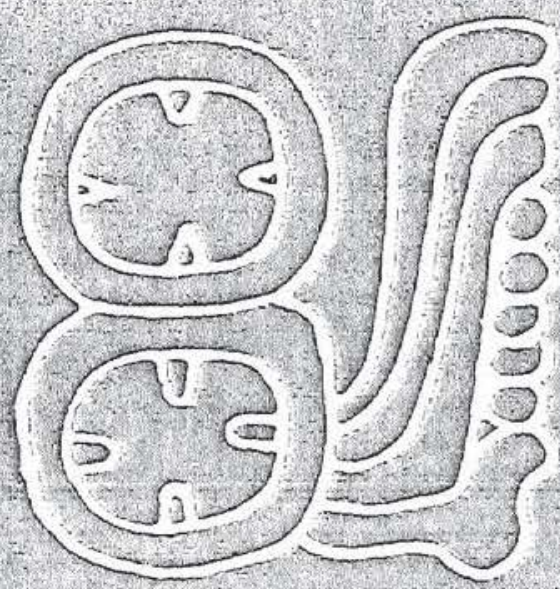


Copyright $\odot 1998$

by Enrique Villanueva

All rights reserved.

No part of this book may be reproduced or utilized in any form or by any means, electrical or mechanical, including photocopying, recording or by any informational storage or retrieval system, without written permission from the copyright owner.

Paper text: ISBN 0-924922-30-3

Cloth (library edition): ISBN 0-924922-80-X

The typesetting was done by José Luis Olivares.

Published in the United States of America

by Ridgeview Publishing Company

Box 686

Atascadero, California 93423

Printed in the United States of America

by Thomson-Shore, Inc. 


\section{Contents}

Preface

Enrique Villanueva

1 There Are No Recognitional Concepts; Not Even RED Jerry Fodor

2 Concept Constitution Paul Horwich

3 Recognitional Concepts and Compositionality Richard Grandy

4 Recognitional Concepts and the Compositionality of Concept Possession

Terence Horgan

5 A More Plausible Kind of "Recognitional Concept" Ruth Garret Millikan

6 Implicit Conceptions, Understanding and Rationality Christopher Peacocke

7 Doubts about Implicit Conceptions Stephen Schiffer

8 What Implicit Conceptions are Unlikely to Do Georges Rey

9 Implicit Conceptions and The Phenomenon of Abandoned Principles

Eric Margolis

10 The Implicit Conception of Implicit Conceptions Josefa Toribio

11 Implicit Conceptions, the $A$ Priori, and the Identity of Concepts

Christopher Peacocke 
12 Conceptual Competence

James Higginbotham

13 The Significance of the Distinction between Concept

Mastery and Concept Possession

Genoveva Martí

14 Conceptual Competence and Inadequate Conceptions Pierre Jacob

15 On Concepts and Conceptions Josep Macià

16 The Concept-Conception Distinction Maite Ezcurdia

17 Response to Commentators

James Higginbotham

18 What the Externalist Can Know A Priori

Paul Boghossian

19 Is There a Good Epistemical Argument against

Concept-Externalism?

Brian Loar

20 Self-Knowledge \& Semantic-Luck

Stephen Yablo

21 A Challenge to Boghossian's Incompatibilist Argument Josep E. Corbi

22 Boghossian's Reductio of Compatibilism Carlos J. Moya

23 Replies to Commentators

Paul Boghossian

24 A Theory of Concepts and Concept Possession George Bealer

25 Bealer's Intuitions on Concept Possession Jaegwoon Kim

26 Concepts and Ontology: A Query for Bealer James E. Tomberlin

27 Getting Clear on the Concept

David Sosa

28 Some Critical Remarks on an Explanation of

Concept Possession

Eleonora Orlando

29 Concept Possession

George Bealer 
30 What Might Nonconceptual Content Be?

Robert Stalnaker

31 Grain and Content

Stephen Neale

353

32 Non-Conceptual Content, Subject-Centered

Information and the Naturalistic Demand

Juan José Acero

33 Report of an Unsuccessful Search for Nonconceptual

Content

Mario Gómez-Torrente

34 Information and Content

David Pineda

381

35 Replies to Comments

Robert Stalnaker

389

Contributors 